EESTI NSV TEADUSTE AKADEEMIA TOIMETISED. 28. KOIDE KEEMIA. 1979, NR. 1

ИЗВЕСТИЯ АКАДЕМИИ НАУК ЭСТОНСКОИ ССР. ТОМ 28 Химия. 1979, № 1

\title{
ХАРАКТЕРИСТИКА ОРГАНИЧЕСКОГО ВЕЩЕСТВА НЕРАБОЧИХ ПЛАСТОВ КАШПИРСКОГО СЛАНЦЕВОГО МЕСТОРОЖДЕНИЯ
}

Органическому веществу (ОВ) сланцев Кашпирского месторождения посвящено довольно много работ, перечень которых приведен в [']. Однако основное внимание в них уделялось пластам, богатым керогеном, ОВ породных прослоек не изучалось, и в литературе данные о нем отсутствуют. В настоящей работе исследовался состав битумоидов и продуктов термической деструкции пород ложной кровли (ЛК) и породной прослойки (ПП) между первым и вторым разрабатываемыми пластами сланца с целью получения данных о возможностях практического использования этих пород и путях генезиса промышленной пачки кашпирских сланцев в целом.

Битумоиды извлекали из обработанных 10\%-ной соляной кислотой пород последовательно смесью бензол-метиловый спирт $(3: 1)$ и диэтиловым эфиром, кислотные соединения выделяли из битумоидов $10 \%$-ным спиртовым раствором гидроокиси калия. Полукоксование дебитуминированных сланцев проводили по ГОСТ 3168-66. Нейтральную часть битумоидов и смолы полукоксования разделяли на групповые компоненты методом тонкослойной хроматографии по методике [ㄹ, газохроматографический анализ проводили на аппарате Хром-4 в условиях программирования температуры на колонках различной полярности.

Исследовавшиеся сланщы существенно различаются по содержанию OB (табл. 1), а также количеству битумоида (табл. 2), хотя в расчете на ОВ выходы последнего близки. Судя по низкому битумоидному коэффициенту $(\beta о в=0,9-1,2)$ и обогащенности экстрактов гетероатомами $\left[{ }^{3}\right]$, битумоиды сингенетичны вмещающей породе. Но все же содержание в них алифатических углеводородов выше обычного, в том числе наблюдающегося в рабочих пластах кашпирского сланца; поскольку в последних битумоида больше $(2-4 \%$ от ОВ), содержание алифатических углеводородов в ОВ примерно одинаковое $(0,3-1,0 \%$ в промышленных, $0,3-0,5 \%$ в нерабочих пластах). В инфракрасных спектрах экстрактов

Таблица 1

Характеристика исходных пород, вес. \%

\begin{tabular}{c|c|c|c|c|c}
\hline Образец & $\mathrm{W}^{\mathrm{a}}$ & $\mathrm{A}^{\mathrm{c}}$ & $\left(\mathrm{CO}_{2}\right)_{\text {нар } 6 .}^{\mathrm{c}}$ & $\mathrm{S}_{\text {общ. }}^{\mathrm{c}}$ & $\begin{array}{c}\text { Условная } \\
\text { органиче- } \\
\text { ская масса }\end{array}$ \\
\hline
\end{tabular}

Ложная кровля

4,8 74,3 10,2 
Таблица 2

Характеристика битумоидов, вес. \%

\begin{tabular}{|c|c|c|c|c|}
\hline \multirow{3}{*}{ Показатели } & Ложная & кровля & Породна & прослойка \\
\hline & \multicolumn{4}{|c|}{ Экстрагент } \\
\hline & $\begin{array}{l}\text { бензол- } \\
\text {-метанол }\end{array}$ & $\begin{array}{l}\text { диэтило- } \\
\text { вый эфир }\end{array}$ & $\begin{array}{l}\text { бензол- } \\
\text {-метанол }\end{array}$ & $\begin{array}{l}\text { диэтило- } \\
\text { вый эфир }\end{array}$ \\
\hline $\begin{array}{l}\text { Выход на сухой сланец } \\
\text { То же на органическую массу }\end{array}$ & $\begin{array}{l}0,105 \\
0,68\end{array}$ & $\begin{array}{l}0,030 \\
0,19\end{array}$ & $\begin{array}{l}0,011 \\
0,73\end{array}$ & $\begin{array}{l}0,007 \\
0,47\end{array}$ \\
\hline \multicolumn{5}{|l|}{ Элементный состав: } \\
\hline $\begin{array}{l}\mathrm{C} \\
\mathrm{H} \\
\mathrm{N}\end{array}$ & $\begin{array}{r}70,5 \\
8,7 \\
08\end{array}$ & $\begin{array}{r}71,9 \\
9,5 \\
-\end{array}$ & $\begin{array}{r}74,0 \\
10,3 \\
0,7\end{array}$ & $\begin{array}{r}66,1 \\
9,5 \\
-\end{array}$ \\
\hline $\begin{array}{l}\mathrm{O}+\mathrm{S} \text { (по разности) } \\
(\mathrm{H} / \mathrm{C}) \text { атом. }\end{array}$ & $\begin{array}{l}20,0 \\
1,48\end{array}$ & $\begin{array}{l}18,6 \\
1,59\end{array}$ & $\begin{array}{l}15,0 \\
1,67\end{array}$ & $\begin{array}{l}24,4 \\
1,72\end{array}$ \\
\hline $\begin{array}{l}\text { Содержание кислотных соединений } \\
\text { из них эфирорастворимых }\end{array}$ & $\begin{array}{l}76,8 \\
46,5\end{array}$ & - & $\begin{array}{l}72,2 \\
67,6\end{array}$ & - \\
\hline \multicolumn{5}{|l|}{$\begin{array}{l}\text { Групповой химический состав } \\
\text { нейтральной части *: }\end{array}$} \\
\hline $\begin{array}{l}\text { неароматические углеводороды } \\
\text { моноциклические ароматические }\end{array}$ & 30 & - & 41 & - \\
\hline $\begin{array}{l}\text { углеводороды } \\
\text { қонленсированные }\end{array}$ & 5 & - & 17 & - \\
\hline $\begin{array}{l}\text { конденсированные ароматиче- } \\
\text { ские углеводороды }\end{array}$ & 3 & - & 4 & - \\
\hline $\begin{array}{l}\text { нейтральные кислородные сое- } \\
\text { динения }\end{array}$ & 62 & - & 38 & - \\
\hline
\end{tabular}

* По основному типу несерусодержащих соединений.

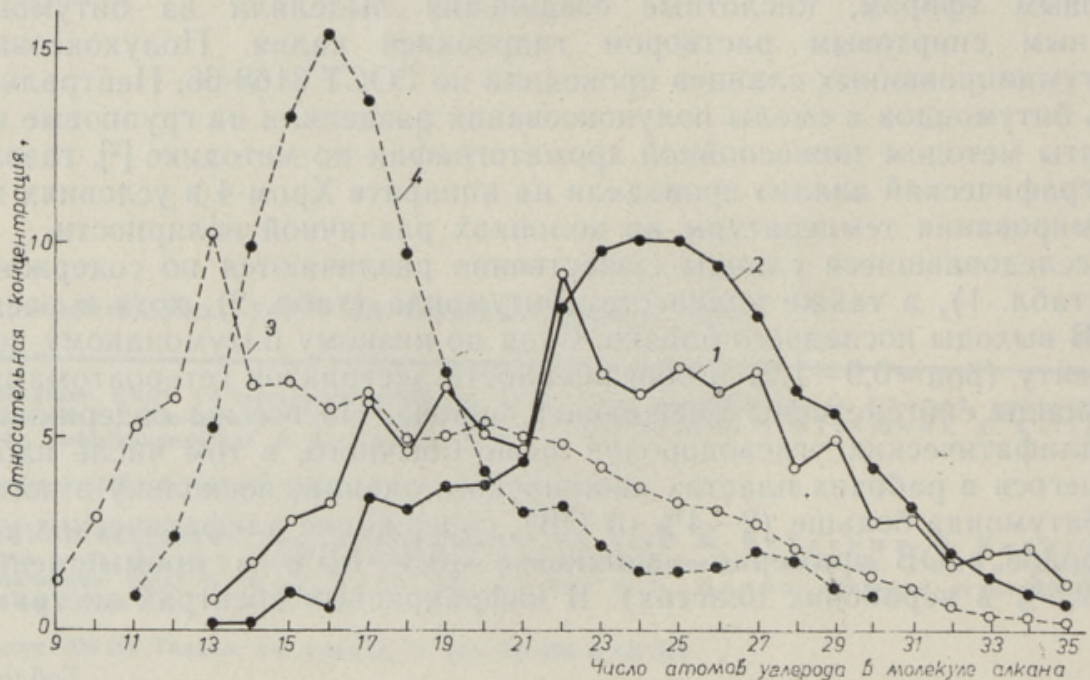

Рис. 1. Распределение по длине цепи $\mathrm{H}$-алканов в битумоидах $(1,2)$ и смолах полукоксования $(3,4)$ пород ложной кровли $(1,3)$ и породной прослойки $(2,4)$.

заметно выражены полосы поглощения карбонильных групп (1700$\left.1750 \mathrm{~cm}^{-1}\right)$, гидроксильных групп с внутримолекулярной водородной связью $\left(2500-3600 \mathrm{~cm}^{-1}\right)$ и длинных углеродных цепей $\left(720 \mathrm{~cm}^{-1}\right)$; полоса $720 \mathrm{~cm}^{-1}$ интенсивнее в случае эфирных битумоидов, что согласуется с повышенным отношением Н/С в них (табл. 2). 


\section{Характеристика смол полукоксования}

Показатели

Выход на сухой сланец, вес. \%

То же на органическую маосу, вес. \%

Элементный состав, вес. \%:

$\mathrm{C}$
$\mathrm{H}$
$\mathrm{N}$
$\mathrm{O}$

$\mathrm{O}+\mathrm{S}$ (по разности)

$(\mathrm{H} / \mathrm{C})$ атом.

Плотность $\varrho_{4}^{20}$

Показатель преломления $n_{D}^{20}$

Групповой химический состав, вес. \%*:

неароматические углеводороды

моноциклические ароматические углеводороды

конденсированные ароматические углеводороды кислородные соединения
Ложная кровля

$\begin{array}{cc}4,16 & 0,19 \\ 26,8 & 12,7 \\ & \\ 79,5 & 79,4 \\ 9,6 & 10,6 \\ 0,8 & 0,8 \\ 10,1 & 9,2 \\ 1,45 & 1,60 \\ 0,9741 & - \\ 1,6471 & -\end{array}$

$13-40$

$27 \quad 10$

$17 \quad 15$

$43 \quad 35$

* См. примечание к табл. 2.
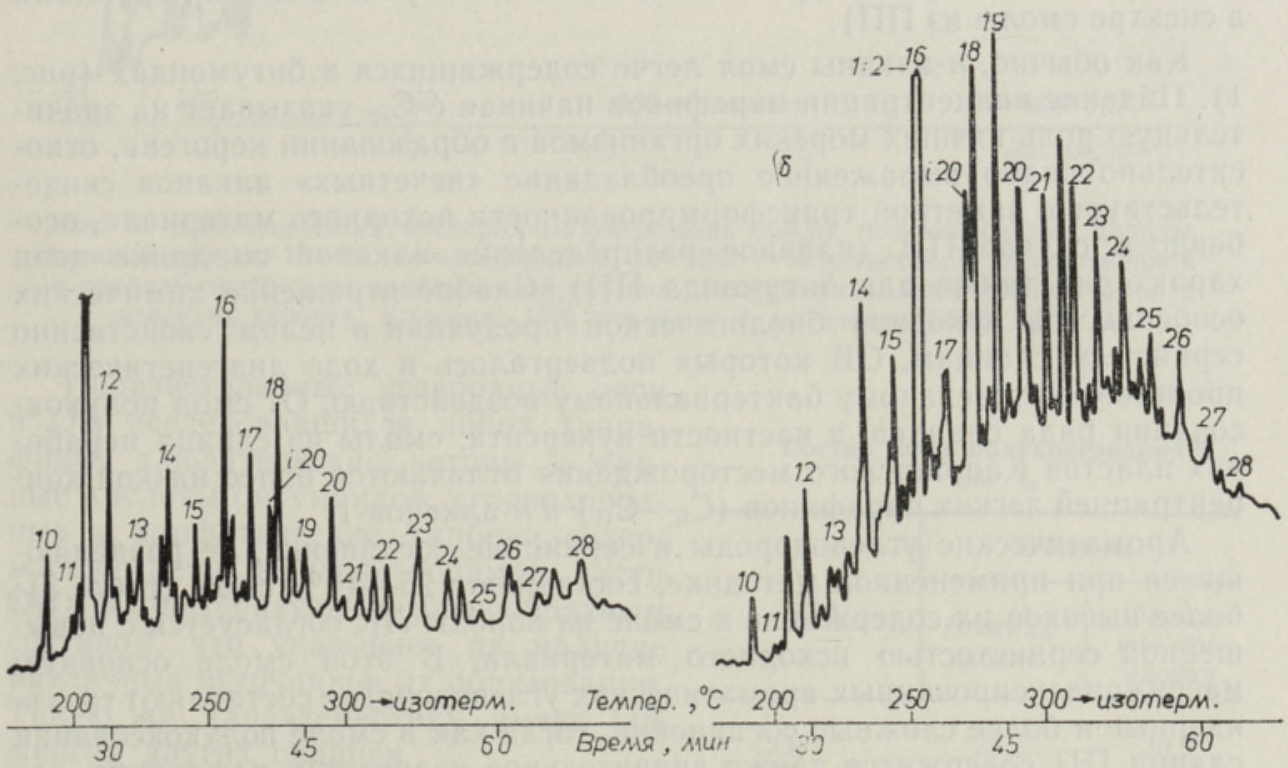

Рис. 2. Хроматограммы метилированных кислотных соединений битумоидов пород ложной кровли (a) и породной прослойки (б). 10-28 - насыщенные жирные кислоты нормального строения, $i 20$ - фитановая кислота (цифры указывают число атомов углерода в молекуле кислоты). Колонка: 7\% Е301 на целите 545, 3,6 м × 3 мм.

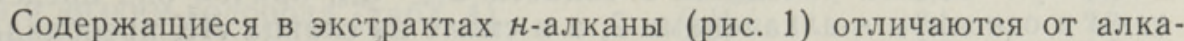
нов сланца промышленных пластов [1] большей средней длиной цепи, в случае породы ЛК - также ярко выраженным преобладанием соединений с нечетным числом атомов углерода в цепи, что, по-видимому, является отражением возросшей роли бактериальной и терригенной биопродукции по сравнению с материалом водных автотрофных организмов в 
связи с менее интенсивной жизнедеятельностью в водоеме при формировании осадка.

В битумоиде породы ЛК обнаружены метил-н-алкилкетоны $\mathrm{C}_{9}-\mathrm{C}_{25}$, в высшей концентрации содержатся н-додеканон-2 и н-тридеканон-2.

Насыщенные жирные кислоты экстрактов (рис. 2) в целом характеризуются преобладанием соединений с четным числом атомов углерода в молекуле и ведущей ролью пальмитиновой кислоты $\left(\mathrm{C}_{16}\right)$, что свойственно многим сланцам, а также ОВ современных осадков. Различия в составе кислот исследовавшихся битумоидов заключаются в более высокой концентрации кислоты $\mathrm{C}_{16}$ и значительно слабее выраженной «четности» кислот в области $\mathrm{C}_{18}-\mathrm{C}_{28}$ в экстракте сланца ПП по сравнению с битумоидом сланца ЛК. Фитановая кислота идентифицирована на основании полученных в аналогичных условиях хроматограмм [ $\left.{ }^{4}\right]$.

Выход смолы полукоксования на кероген заметно различается (табл. 3). Это может быть обусловлено не только неодннаковым составом ОВ, но и влиянием минеральной части; снижение выхода смолы на ОВ с уменьшением его содержания в породе коррелируется с полученными ранее данными. Существенные различия наблюдаются и в составе смол: если смола из ПП заметно обогащена алифатическими углеводородами, то смола из ЛК близка смоле из сланца рабочих пластов [']. Установленные хроматографическими методами особенности состава смол отражаются и в их инфракрасных спектрах (значительно менее интенсивное поглощение кислородсодержащими, особенно карбонильными, группами в спектре смолы из ПП).

Как обычно, н-алканы смол легче содержащихся в битумоидах (рис. 1). Падение концентрации парафинов начиная с $\mathrm{C}_{18}$ указывает на значительную роль низших морских организмов в образовании керогена, относительно слабо выраженное преобладание «нечетных» алканов свидетельствует о заметной трансформированности исходного материала, особенно в случае ПП (плавное распределение алканов по длине цепи характерно также для битумоида ПП). Слабое отражение химических особенностей исходной биологической продукции в целом свойственно сернистым сланцам, ОВ которых подвергалось в ходе диагенетических процессов интенсивному бактериальному воздействию. От смол полукоксования ряда сланцев, в частности кукерсита, смолы из сланца нерабочих пластов Кашпирского месторождения отличаются более низкой концентрацией легких парафинов $\left(\mathrm{C}_{5}-\mathrm{C}_{10}\right)$ и $\boldsymbol{H}$-алкенов-1.

Ароматические углеводороды и сернистые соединения, не разделяющиеся при примененной методике, составляют $25-44 \%$ смол (табл. 3 ); более высокое их содержание в смоле из породы ЛК согласуется с повышенной сернистостью исходного материала. В этой смоле основную массу конденсированных ароматических углеводородов составляют трехъядерные и более сложные соединения, тогда как в смоле полукоксования сланца ПП содержится также значительное количество нафталина, его метил- и диметилпроизводных.

Из кислородных соединений в исследовавшихся смолах идентифицированы метил-н-алкилкетоны и $\boldsymbol{H}$-алканоны с расположенной в средней части цепи карбонильной группой. В смоле из ПП концентрационный максимум кетонов находится в области $\mathrm{C}_{13}-\mathrm{C}_{18}$, причем они представлены в основном $н$-алканонами-2, а в смоле из сланца ЛК преобладают более высококипящие кетоны при значительном содержании симметричных или близких к ним н-алканонов (рис. 3). Более высокое, по сравнению с симметричными кетонами, содержание $H$-алканонов-2 в области выше $\mathrm{C}_{16}$ - для сланцевых смол явление редкое. Раньше это наблюдалось только в случае болгарского сланца месторождения Пирин [ $\left.{ }^{5}\right]$. 


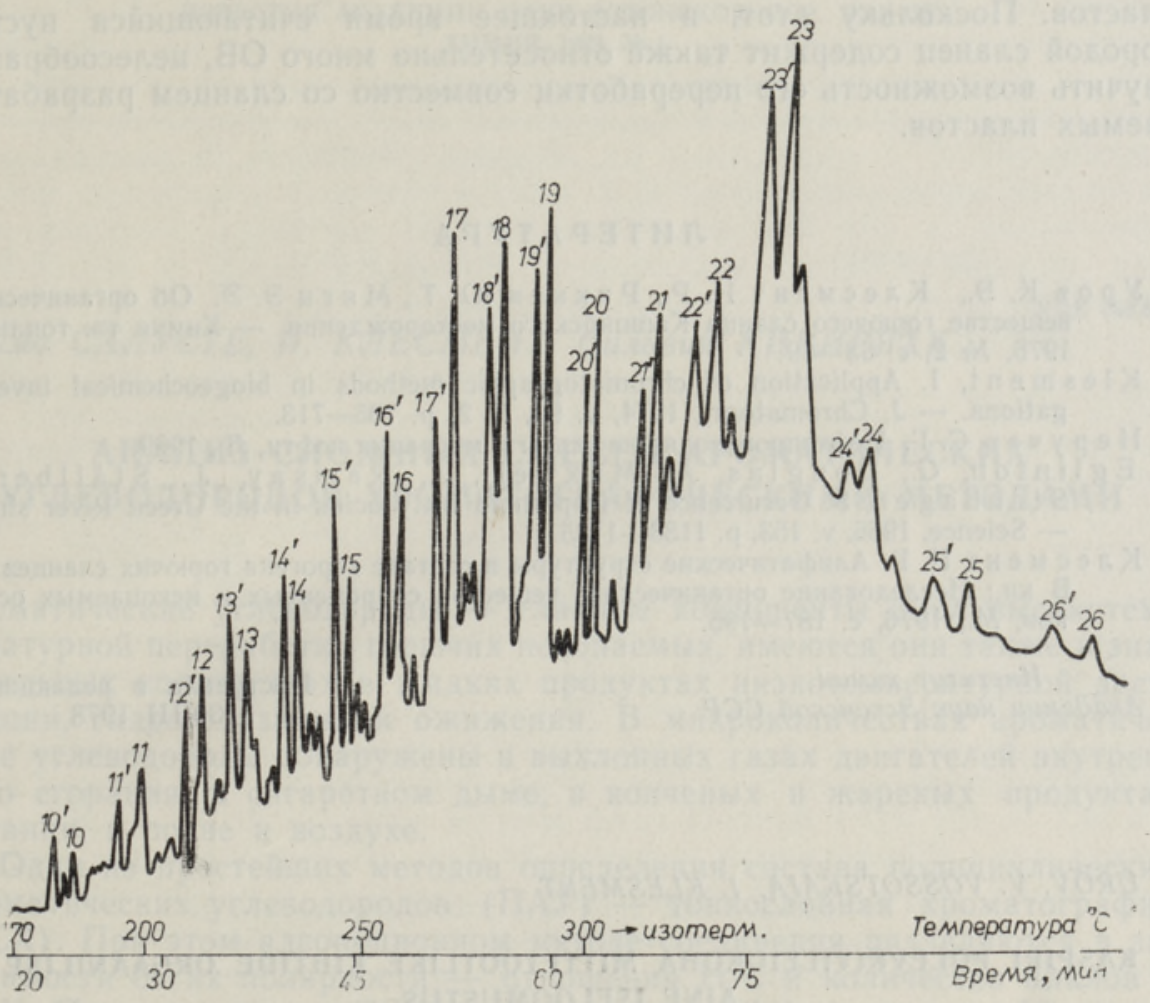

Рис. 3. Хроматограмма кислородных соединений смолы полукоксования породы ложной кровли. $10-26-н$-алканоны- $2,10^{\prime}-26^{\prime}-\mu$-алканоны с расположенной в средней части цепи карбонильной группой (цифры указывают число атомов в молекуле кетона). Колонка: $12 \%$ апьезона $L$ на целите $545,6 м \times 3$ мм.

Неразветвленные углеродные цепи Таблица 4 в ОВ исследовавшихся пород (парафины, алифатические кетоны и жирные кислоты битумоидов, углеводородные и алифатические карбонилсодержащие цепи в нерастворимой части OВ) характеризуются разнообразным составом, что указывает на наличие различных источников их образования. Такую же характеристику имеет ОВ многих других сланцев.

Газ полукоксования сланца ПП отличается от получаемого из сланца ЛК повышенной непредельностью углеводородной части, примерно вдвое более высоким содержанием двуокиси углерода и низким водорода (табл. 4).

Полученные данные свидетельствуют о различном составе битумоидов и продуктов разложения нерастворимой части OB нерабочих пластов кашпирских сланцев, при этом порода ЛК подобна сланцу разрабатываемых

Состав газов полукоксования *, об. \%

\begin{tabular}{l|r|r}
\hline & \multicolumn{2}{|c}{ Габразец } \\
\cline { 2 - 3 } & $\begin{array}{c}\text { Ложная } \\
\text { кровля }\end{array}$ & $\begin{array}{r}\text { Пород- } \\
\text { ная про- } \\
\text { слойка }\end{array}$ \\
\hline & & \\
& & 39,9 \\
$\mathrm{CO}_{2}$ & 21,2 & 14,6 \\
$\mathrm{H}_{2} \mathrm{~S}$ & 30,9 & 4,5 \\
$\mathrm{H}_{2}$ & 11,7 & 1,9 \\
$\mathrm{CO}$ & 1,3 & 23,1 \\
$\mathrm{CH}_{4}$ & 20,7 & 3,5 \\
$\mathrm{C}_{2} \mathrm{H}_{6}$ & 5,0 & 7,8 \\
$\mathrm{C}_{2} \mathrm{H}_{4}$ & 3,2 & 1,3 \\
$\mathrm{C}_{3} \mathrm{H}_{8}$ & 2,4 & 2,2 \\
$\mathrm{C}_{3} \mathrm{H}_{6}$ & 2,1 & 0,5 \\
$\mathrm{C}_{4} \mathrm{H}_{10}$ & 0,6 & 0,7 \\
$\mathrm{C}_{4} \mathrm{H}_{8}$ & 0,9 & 2,65 \\
$\mathrm{C}_{n} \mathrm{H}_{2 n+2}$ & 4,63 &
\end{tabular}

* В расчете на безвоздушный газ. 
пластов. Поскольку этот, в настоящее время считающийся пустой породой сланец содержит также относительно много ОВ, целесообразно изучить возможность его переработки совместно со сланцем разрабатываемых пластов.

\section{Л И ТЕ Р А Т Р А}

1. Уров К. Э., Клесмент И. Р., Риккен Ю. Т., Мяги Э. Э. Об органическом веществе горючего сланца Кашпирского месторождения. - Химия тв. топлива, 1976 , № 2 , c. $63-69$.

2. Klesment, I. Application of chromatographic methods in biogeochemical investi gations. - J. Chromatogr., 1974, v. 91, N 2, p. 705-713.

3. Н е р у ч е в С. Г. Нефтепроизводящие свиты и миграция нефти, Л., 1969.

4. Eglinton, G., Doug 1 a s, A., $M$ a x well, J., Ramsay, J., S t ä 11 berg. $\mathrm{S}$ t e $\mathrm{n}$ h a g e n, S. Occurrence of isoprenoid fatty acids in the Green River shale. - Science, 1966, v. 153, p. 1133-1135.

5. К л е с м н т И. Р. Алифатические структуры в составе керогена горючих сланцев. В кн.: Исследование органического вещества современных и ископаемых осадков, М., 1976, с. $187-195$.

Институт химии

Академии наук Эстонской ССР
Поступила в редакцию 30/III 1978

K. UROV, V. VOSSOTSKAJA, I. KLESMENT

\section{KAŠPIRI PÕLEVKIVILEIUKOHA MITTETOOTLIKE KIHTIDE ORGAANILISE AINE ISELOOMUSTUS}

Kašpiri leiıkoha kahe kerogeenivaese, aheraineks loetava vahekihi orgaaniline aine erineb omavahel märgatavalt nii ekstraktide kui ka termilise lagunemise saaduste koostise poolest. Ulemisel kaevandataval kihil lasuva kihi põlevkivi, mis orgaanilise aine $(15,5 \%$ kivimist) iseloomu poolest sarnaneb tootlike kihtidega, kujutab endast võimalikku tööstustoorainet.

\section{CHARACTERIZATION OF ORGANIC MATTER OF NON-PRODUCTIVE STRATA OF KASHPIR SHALE DEPOSIT}

The chemical composition of the organic substance of rock samples from two strata, poor in organic matter, of Kashpir shale deposit have been investigated. It is established that the samples investigated are considerably different in respect to the composition of bitumen and thermal degradation products. The shale of the stratum spreading over the first mined seam of shale whose organic matter $(15,5 \%$ of the rock) is similar to that of the productive beds, may be regarded as a possible raw material for semi-coking and power production. 